\title{
Miradas en metamorfosis: una investigación estética sobre la producción puntual de un artista anónimo
}

\section{Looks in metamorphosis: an aesthetic research on the timely production of an anonymous artist}

\author{
TIPO DE TRABAJO: Comunicación.
}

PALABRAS CLAVE

Arte contemporáneo. Génesis. Recepción estética. Percepciones visuales. Transfiguraciones.

KEY WORDS

Contemporary art. Genesis. Aesthetic reception. Visual perceptions. Transfigurations.

RESUMEN

Dentro de la escena artística contemporánea, convivimos con conceptos diversos; enfrentamos teorías divergentes; hibridamos técnicas y nuevas tecnologías; borramos fronteras entre lenguajes y géneros artísticos. Así, frente a la complejidad y riqueza de este panorama artístico: ¿podríamos afirmar que nos descubrimos en plena metamorfosis? El trabajo investigativo, centrado en el tema Miradas en Metamorfosis, busca apropiarse del mismo arte para examinar, reflexionar y cuestionar el arte contemporáneo en relación con el espectador - sus gustos, afectos, inferencias, consumos e interpretaciones -, en especial, el gran público no inicializado en el mundo del arte. A partir de esta idea, este proyecto posibilitará la creación de obras híbridas, que representen las diferentes transformaciones que puede sufrir una obra, hasta el momento de su mayor y más significativa metamorfosis, que está en la mirada del espectador sobre ella. ¿Qué aspectos esenciales un artista deberá tener en cuenta en la producción de una obra que venga a sensibilizar a un lector "común"? ¿Qué tiempos y valores se encuentran insertados en una obra? ¿De qué forma el arte visual contemporánea está llegando al público general? Cabrá al artista no sólo el desafío de inducir al cuestionamiento y reflexión sobre estos temas, mas, sobre todo, buscar y presentar respuestas plásticas e icónicas para estas cuestiones, enfatizando principalmente el compromiso del arte con el público no especializado. El resultado plástico final de la investigación será presentado en una exposición llamada Ver en el tiempo: derivas poéticas, en la que las obras sufrirán transformaciones a lo largo de toda la exhibición. La metodología llevará en cuenta que la producción artística de la investigación será elaborada pari passu con el desarrollo del proyecto investigativo. Los textos elaborados deberán contemplar un análisis poético y poiético de los elementos y factores que llevarán a la realización de las obras y su génesis.

\section{ABSTRACT}

Within the contemporary art scene, we coexist with several concepts; we face divergent theories; we hybridise techniques and new technologies; we erase borders between languages and artistic genres. Thus, in the face of the complexity and richness of this artistic panorama: could we assert that we discover ourselves in the metamorphic process? This research, focused on the topic Looks into Metamorphosis, seeks to appropriate the same art in itself to examine, reflect and question contemporary art in relation to the viewer - his tastes, affections, inferences, consumption and interpretations -, especially regarding the general public yet initialised in the world of art. Building on this idea, this project will enable the creation of hybrid works, which symbolize the different transformations that a work can undergo, until the moment of its greatest and most significant metamorphosis, which lays on the viewer's gaze upon it. What essential aspects should an artist take into account in the production of a work that comes to sensitise a "common" reader? What times and values are inserted in a work? In what way is contemporary visual art reaching 
the general public? The artist will not only be challenged to induce questioning and reflection on these issues, but, above all, to seek and to present plastic and iconic responses to these issues, emphasising mainly the commitment of art to the non-specialized public. The final plastic result of the investigation will be presented in an exhibition called Seeing into time: poetic drifts, in which the works will undergo transformations throughout the entire exhibition. The methodology will take into account that the artistic production of the research will be elaborated pari passu with the development of the research project. The target texts must contemplate a poetic and poietic analyses of the elements and factors that will lead to the realization of the works and their geneses.

\section{INTRODUCCIÓN}

Pese a ser, en alguna medida, una continuación de la investigación CORPOdiVERsidade: uma reflexão artística sobre a forma humana e suas transformações desarrollada para mi Máster en Producción Artística en la Universidade Federal da Bahia, Brasil, el tema que ahora estudio no tiene como objeto el cuerpo humano y sus transformaciones, sino las posibles metamorfosis por las que pasa una obra artística. Me basaré, para ello, en trabajos realizados por un artista anónimo al que me refiero como Arán. Estas obras se expondrán en una muestra titulada Ver en el tiempo: una deriva poética, en la sala de exposición de la Biblioteca Eduardo Escalante, ubicada en la ciudad de Valencia. Se ha estipulado que el tiempo de duración de la muestra será de apenas un mes, por la necesidad de acompañar todo el proceso de cambios de las obras expuestas.

Es importante puntuar que la investigación, sintetizada en el conjunto génesis-progreso-recepción, se encuentra en proceso de ejecución, por lo que no se presentan en este artículo ningún resultado ni obras finalizadas, sino reflexiones acerca de los temas que forman parte del eje central de este artículo: los públicos, los tiempos de una obra y la importancia de ser una muestra de un artista anónimo.

\section{INVESTIGANDO LA PERFORMANCE}

Lo que debe aparecer es la obra y no el artista, pues éste ya es inherente a ella. Así le contesté a mi profesor de la asignatura Performance del curso de Máster, cuando me preguntó por qué yo no presentaría ninguna performance en mi Trabajo Final de Máster. Como el tema de la disertación trataba de las modificaciones corporales y sus hibridaciones, decidí que mi trabajo de doctorado podría abordar el tema de la performance, pero no de la performance de un artista o de un cuerpo de otra persona, sino de la transformación del propio cuerpo de la obra artística, es decir, su performance a lo largo de la exposición.

Con la obra Diga-me algo (Figura 1), que formaba parte de la exposición CORPOdiVERsidade: uma nova antropomorfia, resultado de la producción artística del Máster, ya señalaba mi interés por la opinión del espectador. Como artista, a menudo me importó saber sobre la reacción del público en relación con las obras que producía. Siempre tuve en mente que creaba las obras para los demás, y su experiencia estética era algo que me interesaba.

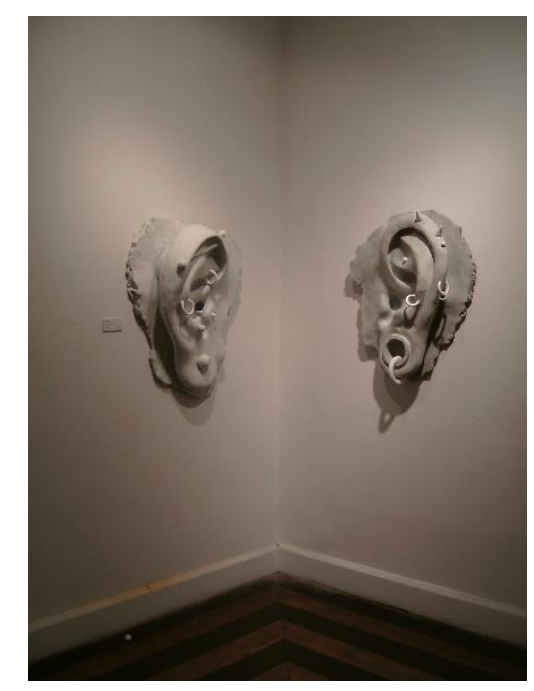

Figura 1. Instalación, “Diga-me algo”, Eduardo Góes, 2011 (Elaboración propia) 
Desde estas dos premisas surgió la idea generadora del estudio, que tiene como objetivo investigar y problematizar las diversas miradas, en metamorfosis, por las que pasan las obras artísticas de un autor anónimo, tomándose en consideración los diferentes momentos y tiempos de su transformación desde la multiplicidad de formas de resolver la praxis.

Para ello, se propone un recorrido a través de un elemento específico: la metamorfosis; desde el concepto de transformación de trabajos visuales del artista Arán, los que cambiarán de aspecto, presentación y sentido a lo largo de la exposición, hasta las distintas miradas del gran público hacia cada obra.

En un primer momento de este artículo, entonces, se llevan a cabo reflexiones acerca del arte contemporáneo y sus públicos. A continuación, se ve cómo pueden clasificar o cuáles son los tiempos de una obra artística, desde su génesis hasta su desaparición o momento final. Se concluye explicando los motivos y la importancia de trabajarse con un artista anónimo en esta investigación.

\section{MIRADAS SOBRE EL ESCENARIO ARTÍSTICO CONTEMPORÁNEO Y SU PÚBLICO}

Como artista, profesor e investigador, siempre me ha resultado curiosa la frase, frecuente, "me gusta el arte, pero no lo entiendo". El diversificado público actual, iniciado o no en el mundo del arte, se encuentra, cada vez más, bombardeado por imágenes presentadas en exposiciones, museos, galerías, centros culturales, revistas y libros de arte, e incluso en espacios públicos reales y virtuales. ¿Se podría afirmar que vivimos en una plena "estetización de la vida" en la que la imagen impone su dictadura silenciosa y muchas veces incomprensible?

Pero ¿cómo reaccionamos ante todo este panorama? En los últimos cien años pasamos por momentos de grandes revoluciones científicas, políticas, sociales, filosóficas, ideológicas y estéticas. En el mundo del arte convivimos con diferentes manifestaciones artísticas, creamos otros lenguajes, ejecutamos nuevas técnicas, profesamos manifiestos, replanteamos conceptos, cambiamos el modo de hacer arte, rompimos con los valores clásicos, abrimos espacios para las artistas mujeres, implementamos mediaciones en las escuelas y en visitas guiadas, elaboramos debates públicos, escribimos innúmeros libros, disertaciones y tesis en arte, y globalizamos el arte en las grandes ferias y en las espectaculares bienales.

Hablamos demasiado sobre arte contemporáneo y, sin embargo, aún muchos de nosotros seguimos rechazándolo por incomprensión o indiferencia. Actualmente, aunque tengamos toda esta gama de informaciones y experiencias en el campo del arte, hay todavía poco interés del público por las producciones artísticas actuales.

La forma en que el arte contemporáneo sigue siendo pensado, realizado y consumido es una gran incógnita. Solamente los agentes del Sistema de Arte se encuentran cómodos en este insólito mundo artístico protegido y generado por su propia legitimidad. El público especializado del mercado del arte, del que forman parte los directores de museos, los comisarios, los galeristas, los coleccionadores, los críticos y algunos artistas, iniciados en los grandes misterios de la estética, se ha alejado del gran público. Y lo más grave de esta realidad es que muchos de estos agentes del arte contemporáneo continúan trabajando para que el arte siga sirviendo para diferenciar una clase social determinada.

Un estudio de caso realizado en Mallorca, por la profesora crítica de arte Ana Ferrero Horrach, sobre la percepción social del arte y del artista contemporáneo, demuestra que existe actualmente un distanciamiento muy grande entre público y artistas. En una entrevista con Juan Antonio Horrach (2014), director de la Galería Horrach Moya, una de las galerías más importantes de Mallorca y con mayor proyección internacional, se nota perfectamente el desinterés por el tema:

Creo que las barreras en el arte contemporáneo están muy bien, deben existir, ya que considero que el arte contemporáneo no tiene por qué llegar a todo el mundo. El arte no se puede banalizar y somos los galeristas quienes tenemos que preservar los parámetros de la alta cultura para mantener la excelencia en el arte. El arte es eso que se muestra en los espacios dedicados al arte, aquellos espacios que hacen las cosas bien, que conservan el contexto del arte: la forma de contemplarlo, el espacio adecuado, etc. (https://www.youtube.com/watch?v=uGsnFpsf1ro\&t=114s)

Es demasiado preocupante saber que algunos de estos agentes, que subvencionan el arte actual, defiendan de manera tan vehemente ideas de esta naturaleza.

Toda obra artística es un objeto de comunicación, por lo tanto, transmite un mensaje creado por un artista y direccionado a un receptor o "público". La producción artística siempre dependió de patronos que dinamizaron y fomentaron los trabajos de los artistas. En este contexto, se encuentran los mecenas del Renacimiento, las jerarquías de poder, representadas por la Iglesia y por el Rey, los marchands, las asociaciones, y en nuestros días, los nuevos mecenas, léase instituciones, empresas nacionales e internacionales, bancos, fundaciones y particulares. Entre los patronos y el público se destacan los clientes, que, con su alto estatus socioeconómico, influyen en el éxito o no de una tendencia o corriente. Y el público, el último de los tres estamentos, que al contrario de los dos anteriores, no influencia, a través de sus gustos particulares, el mercado del arte.

Así, la exposición estará direccionada particularmente a este gran público, pues se pretende observar y registrar sus gustos y percepciones. La gente de la calle será el principal receptor y personaje de esta investigación, puesto que estas obras artísticas no tendrían significado sin sus miradas y sin su participación. 


\section{METAMORFOSIS CREATIVAS: TIEMPOS DE LA OBRA}

Según Teresa-M Sala (2017), la "etimología de la palabra metamorfosis indica una alteración de la forma, un proceso de transformación irreversible que hace referencia a la mutación, evolución o cambio de una cosa que se convierte en otra diferente" (p.179). Se añaden, entonces, además del cambio de forma, las transformaciones perceptivas y significantes en relación con los objetos artísticos, los que, como todas las demás substancias, se encuentran en contantes alteraciones. En la idea de metamorfosis están inscritas las figuras híbridas, combinadas y entrelazadas en la dimensión tiempo. No se podrían abordar las clases de metamorfosis que puede sufrir un trabajo artístico sin nombrar la misteriosa figura del tiempo.

Se dividen, así, los tiempos de un trabajo artístico en los siguientes momentos: tiempo de las ideas o génesis, tiempo de la aprehensión de la idea, tiempo de la poiesis o de la producción, tiempo de exposición y de fruición, y tiempo de vida de una obra. En cada período, la obra artística pasa por diferentes metamorfosis, con diferentes velocidades de transformación. No se abordan en este artículo, sin embargo, las clases de cambios por las que pasarán las obras artísticas de la exposición, sino sus períodos de transformación.

¿En qué momento nace una obra de arte? Esta es una cuestión muy subjetiva y difícil de contestar, porque la idea, el impulso primero, la primera chispa de algo a concretizarse, es muy imperceptible, voluble e inmaterial. Sobre este tema, Arán nos cuenta que la idea de sus trabajos artísticos le llega de una forma silenciosa y delicada o salvaje y potente, en momentos programados o inesperadamente. Fruto de una búsqueda incesante o de una sorpresa agradable y encantadora, para él, la idea de una obra es siempre una visita bienvenida, que no debería dejar escapar.

Como el artista plástico trabaja con el aspecto visual del mundo, el primer paso de su creación es romper el terror del papel en blanco. Su idea debe hacerse visible a través de un pequeño dibujo, un boceto, un estudio en el que pueda visualizar los aspectos formales de su futura obra y así transformarlos borrando o añadiendo nuevos elementos. Es el tiempo del pensar la obra artística, momento para estudios de soluciones, reflexiones y nuevos procedimientos y deliberaciones (Figura 2).

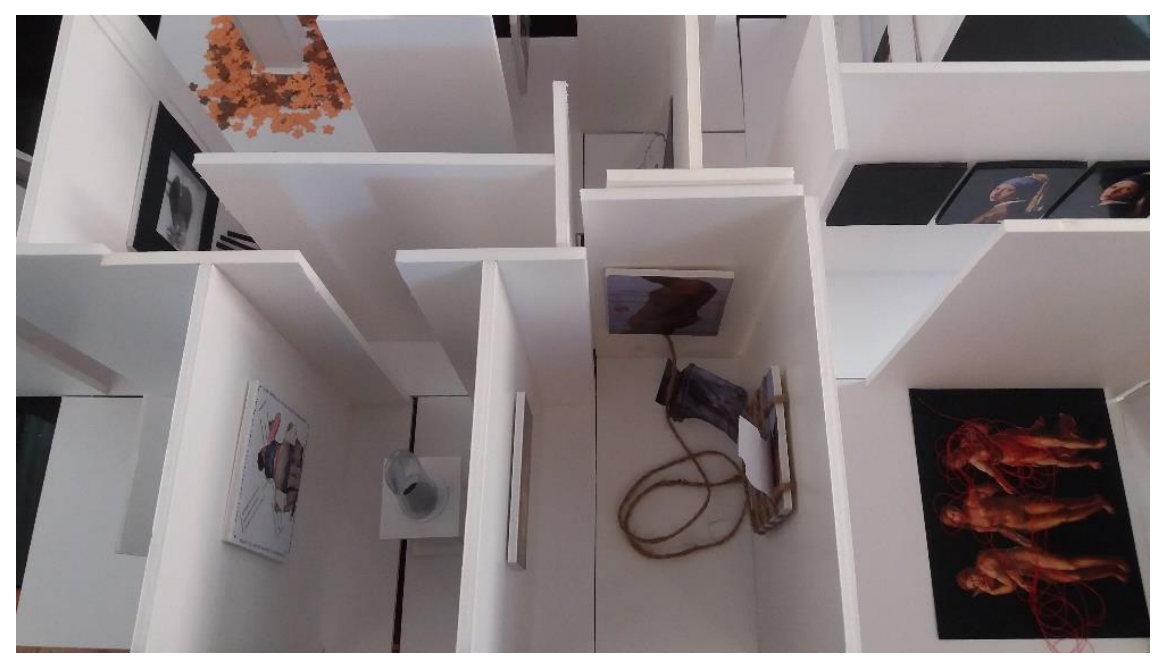

Figura 2. Estudios en maquetas, Arán, 2019 (Fotografía del autor)

Con la idea ya aprehendida en una hoja de papel, llega el tiempo de la poiesis, es decir, el momento de la producción y construcción del cuerpo matérico de la obra (Figura 3). Cada artista tiene su velocidad y ritmo propio de elaboración de su trabajo. Para Arán, por ejemplo, es un tiempo distinto del tiempo real, pues está formado por instantes seguidos que exigen máxima atención y compromiso con lo que hace. Es el olvido del tiempo exterior del cotidiano, que vence el cansancio, el hambre. Para él es el tiempo sin prisa. 

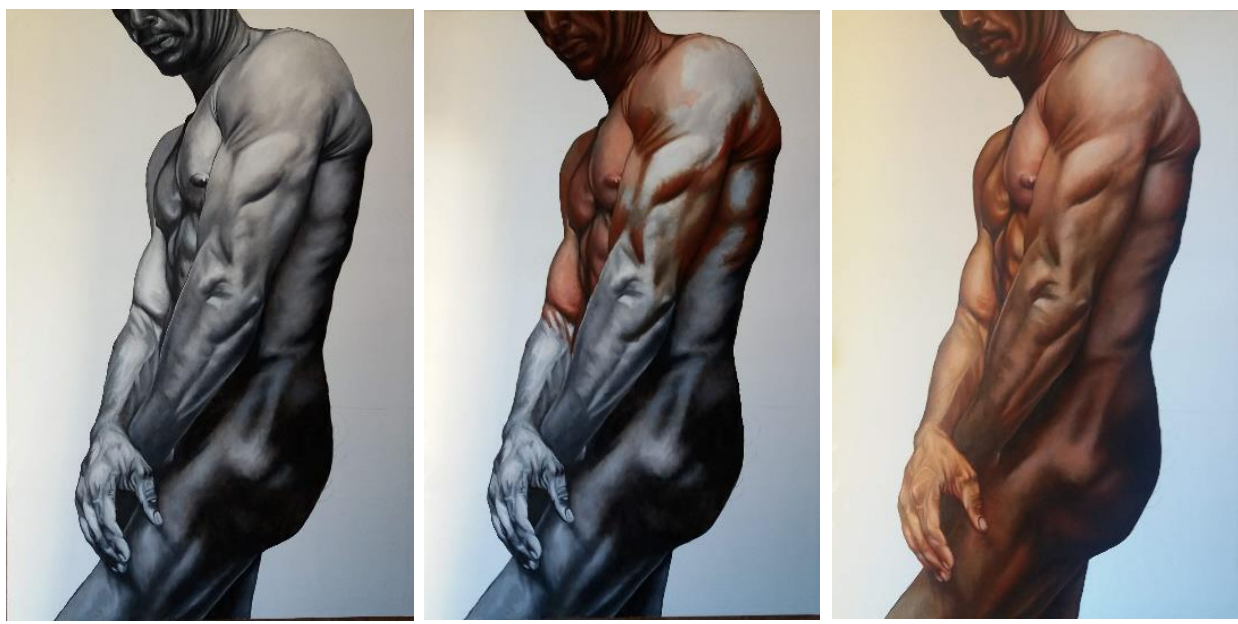

Figura 3. Pintura, fases de producción, Arán, 2019

(Fotografía del autor)

Balzac (2012), a través del Mestre pintor Frenhofer, personaje del libro A Obra Prima Ignorada, nos señala que la pintura de un cuadro es una obra de paciencia.

O belo é uma coisa austera e difícil que não se deixa apreender assim; é preciso respeitar seu tempo, observá-lo, estreitá-lo e abraçá-lo estreitamente para forçá-lo a entregar-se. (...) Vocês, vocês se contentam com a primeira aparência que a forma oferece, no máximo com a segunda ou a terceira; não é assim que agem os combatentes que saem vitoriosos! (...) Mas vocês se cansam depressa demais ${ }^{1}$ (p.19).

Muchas obras artísticas contemporáneas carecen de este tiempo de gestación, de madurez. Como trabajos que reflejan el espíritu de su propio tiempo, el arte actual exige velocidad, pragmatismo y prontitud. La emoción de una pincelada, de un trazado o de un gesto escultórico es sustituido por la razón, el concepto, la idea central. "E quando o raciocínio e a poesia brigam com os pincéis, o resultado é a dúvida. Os pintores só devem meditar com os pincéis nas mãos” (Balzac, 2012, p.30).

¿Qué factores llevarían a un espectador a detenerse por más tiempo ante una obra artística? Se podría afirmar que esta relación entre obra y espectador se resumiría a principio en un sentimiento de atracción o reproche, y que dependería tanto de los aspectos de la obra y de su contenido, como del aspecto psicológico y físico de quien la mira. Es una relación muy subjetiva. Del punto de vista del espectador, la fruición de la obra puede ser determinada por diversos factores: identificación o familiarización con algún elemento del trabajo, disponibilidad física y psicológica, interés por el tema, atracción visual, cantidad de obras en la exposición, número de visitantes, curiosidad, tiempo disponible etc.

Si una misma obra de arte, sin cambiar sus características estéticas, puede suscitar diferentes experiencias en los espectadores, esta misma experiencia podría ser enriquecida si la obra se metamorfoseara ante su mirada. Y es esta práctica con la que se intentará provocar al público durante la exposición.

Al contrario de lo que hacían los antiguos artistas, muchas obras artísticas contemporáneas no son hechas para la eternidad. Su tiempo de duración depende de diversos factores: de sus materiales, de su técnica, de su lenguaje, de la decisión del propio artista etc. Muchas obras actuales son producidas con objetos de desechos, con elementos orgánicos o con materiales que sufren fácilmente la acción de la naturaleza. Son obras que trabajan con la naturaleza provisoria y con la brevedad; trabajos que se pierden a lo largo del tiempo. Como ejemplos se pueden citar la obra Mil Años de Damien Hirst, las obras auto destructivas de Gustav Metzer y las obras escultóricas de Jason de Caires Taylor, sumergidas en el océano. Están también los trabajos que tienen su durabilidad determinada por el propio artista, como en el caso del ninot de Felipe VI de Santiago Sierra y Eugenio Merino, presentado en Arco 2019, que será quemado dentro de un año.

Arán, artista anónimo, también presentará en la exposición que sirve de base a la investigación, obras que serán alteradas por la presencia de los visitantes, destruidas por su acción (Figura 4) y videos que tienen, por su propia naturaleza, un tiempo estipulado de lectura (Figura 5).

${ }^{1}$ Lo bello es una cosa austera y difícil que no se deja aprehender así; es necesario que se le respete su tiempo, observarlo, estrecharlo y abrazarlo apretadamente para obligarlo a entregarse. (...) Ustedes, ustedes se satisfacen con la primera apariencia que la forma ofrece, como mucho con la segunda o la tercera; no es así como actúan los combatientes que acaban victoriosos. Pero ustedes se cansan demasiado pronto (Traducción del autor). 


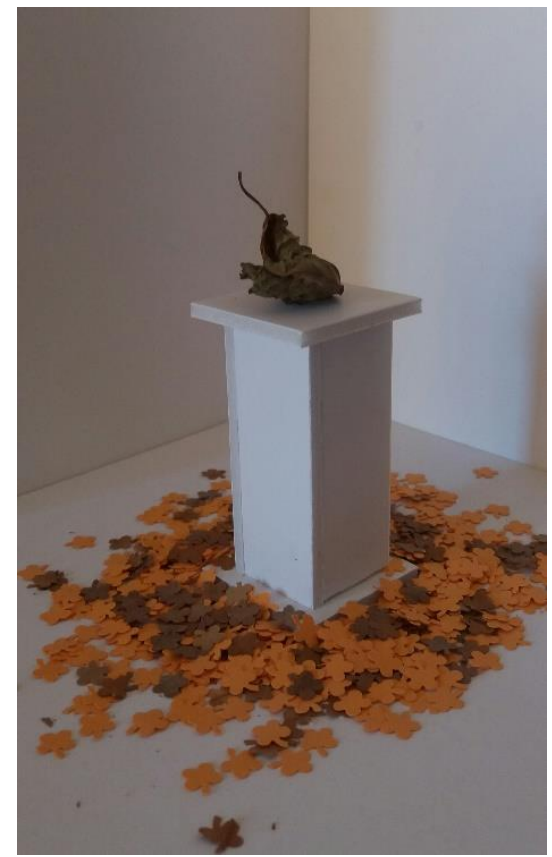

Figura 4. Estudio en maqueta, Arán, 2019 (Fotografía del autor)

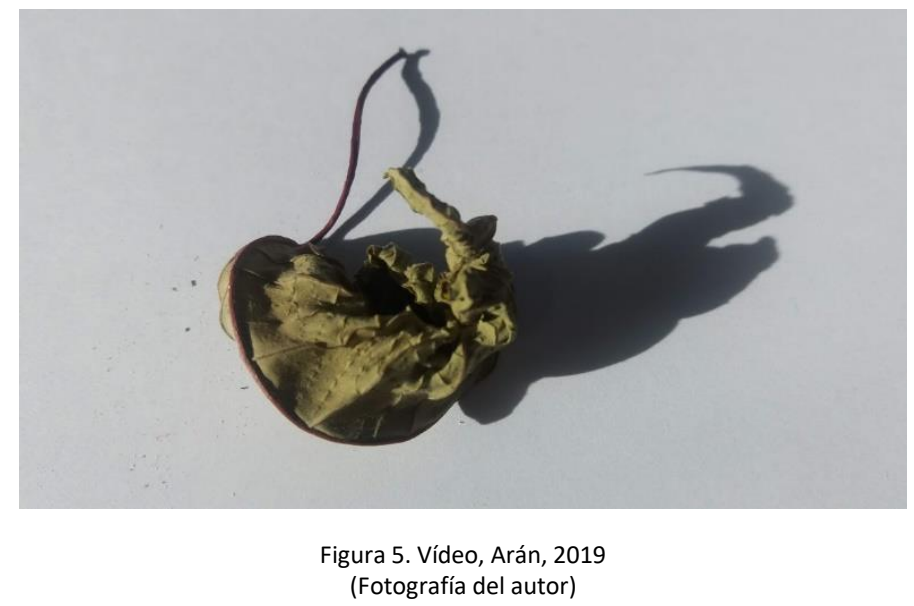

\section{UN ARTISTA ANONIMO}

El artista plástico ha sido, a lo largo de la historia, un personaje en transformación, pues su relación con la sociedad de su tiempo y su representación social han ido variando en el tiempo. Han sido vistos como seres divinos, personas bendecidas por los dioses, personas iluminadas, intelectuales, constructor de identidades y de ideas, más también, individuos peligrosos para la armonía de las polis, grandes rebeldes y revolucionarios, activistas, extravagantes, subversivos, locos, y, en nuestros días, profesionales que se manejan en el mercado del arte. Para Sarah Thornton (2015), los artistas contemporáneos forman parte de un "grupo de profissionais que é cada vez mais exposto mundialmente como indivíduos por excelência, dotados de liberdades invejáveis" 2 (p.12).

El oficio de artista visual contemporáneo es un constante movimiento de hacerse visible, un exhaustivo ensayo de auto gestión de su profesión y de su propia imagen. Tiene que producir trabajos que interesen al Sistema de Arte, debe participar de convocatorias,

${ }^{2}$ Grupo de profesionales que está cada vez más expuesto mundialmente como individuos por excelencia, dotados de libertades envidiables (Traducción del autor). 
competencias artísticas y becas, ser elegido por algún comisario o galerista y formar parte de las principales redes sociales para que no caer en la trampa de la desaparición. La profesora y crítica de literatura, Milena Britto (2017), muestra un modelo de escritor nuevo:

...o escritor que tem de pensar a si mesmo como gestor, que tem de transformar a sua criação em um projeto com características financeiras, estéticas, sociais e políticas. O autor passa a ser gestor de um projeto e, portanto, de sua própria carreira, a qual pode passar a existir a partir da

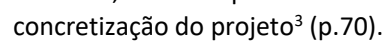

No muy diferente de este escritor contemporáneo al que se refiere Britto, el artista visual actual irrumpe un espacio híbrido de productor, lector, crítico, gestor y publicitario de su propia producción, llevando en cuenta que no puede descuidarse en ningún momento de su trabajo estético creativo. El artista contemporáneo tiene que replantearse a cada momento, debe estar siempre en movimiento y explicarse a sí mismo y a los demás.

El artista anónimo en el que se basa esta investigación sigue justamente el camino contrario de los demás artistas visuales contemporáneos. Ni su nombre ni su imagen formarán parte del proceso. Tendrá su identidad velada a lo largo de toda la muestra. No enseñará ninguna obra ni divulgará su exposición con su nombre artístico en las redes sociales.

La propuesta de elegir a un artista anónimo se debe al hecho de intentar buscar una mirada lo más limpia posible del espectador en relación con las obras artísticas. Es evidente que jamás llegaremos a obtener una mirada de tal naturaleza, pues como seres humanos, estamos repletos de valores, conceptos, experiencias, prejuicios, gustos y otros aspectos inherentes a nuestra personalidad individual y social. No obstante, la finalidad de esta exposición es dejar que las obras hablen por sí mismas. Para ello, se decidió sacar todas las informaciones posibles que pudieran añadir valores externos a la propia obra: fechas, técnicas, lenguajes, autor, mediaciones y textos explicativos. Cada obra deberá hablarle directamente al visitante sin interferencias, contaminación o valor agregado. Su presencia y título serán los únicos elementos necesarios para su lectura e interpretación.

Arán será un personaje fundamental en la construcción de la idea central de esta investigación, es decir, en la metamorfosis de las obras desde su ideación hasta su exposición. Participará no sólo de la función de simple ejecutor de las obras artísticas, sino también de la producción subjetiva de cada una de ellas. Cómo y cuándo surgieron, sus materiales, lenguajes, ideas y temas centrales, técnicas utilizadas, dificultades y soluciones encontradas durante la ejecución, maniobras de producción, cambios de ideas y recorridos, equívocos, resistencias, formas de transformaciones que sufrirán, y modos de ser expuestas. Todas estas informaciones serán elementos claves para la construcción de la tesis. Todo el proceso será registrado por él a través de notas, bocetos, maquetas, fotografías, videos, presentado finalmente como un diario de producción. Se busca una metamorfosis del artista productor en artista archivista, creada a partir de una relación directa de contacto consigo mismo. Como artista, tengo conciencia de que estar presente y consciente del proceso creativo de tamaña magnitud es un ejercicio de actividades delicado, poético, exhaustivo y complejo.

\section{CONSIDERACIONES FINALES}

Para finalizar, momentáneamente, se señala que en el mundo del arte contemporáneo hay público para todos. Se intenta, de esta forma, presentar a la gente de la calle una exposición con obras artísticas hechas para ellos. Una muestra que pueda acercar los trabajos al gran público y comunicarles, de forma agradable, sin buscar impactar o crear confusión o desconcierto. Obras que rompan la indiferencia y que permitan reflexionar y profundizar sobre el arte contemporáneo a través del propio arte. Se espera producir obras que puedan ser leídas según la capacidad intelectual y sensibilidad de cada uno, igual que las grandes parábolas y mitos. De acuerdo con la idea de Ricardo Basbaum (2013), nuestra mayor expectativa es hacer que el individuo entre en la exposición como "público" y salga como "espectador". Para él, "público" es caracterizado por números o estadísticas clasificatorias, mientras "espectador" revelaría un individuo identificado con la obra, involucrado con la experiencia de fruición sensorial y subjetiva. Arte es diálogo.

Adoptando una metodología cualitativa, el texto final será presentado en otro momento abordando los aspectos subjetivos y formales de cada obra, desde su génesis y su proceso de ejecución, hasta el momento final de su presentación al público, cuya mirada será investigada a través de cuestionarios, entrevistas, registros fotográficos y de videos. Se espera dar voz a los diferentes espectadores visitantes, para que puedan juzgar el arte a partir de sus propias experiencias y percepciones, sin ninguna contaminación, hasta donde sea posible, de opiniones de especializados en arte.

${ }^{3}$ El escritor que tiene que pensarse a sí mismo como gestor, que tiene que hacer de su creación un proyecto con características financieras, estéticas, sociales y políticas. El autor pasa a ser gestor de un proyecto y, por lo tanto, de su propia carrera, la cual puede venir a existir a partir de la concreción del proyecto (Traducción del autor). 


\section{FUENTES REFERENCIALES}

Balzac, H. de (2012). A obra prima ignorada (Teixeira Coelho, trad.). São Paulo, Brasil: Iluminuras.

Basbaum, R. (2013). Manual do artista-etc. Rio de Janeiro, Brasil: Beco do Azougue.

Britto, M. (2017). Afetar a cena literária: política, afinidade, estratégias e autogestão entre os autores contemporâneos. En L. Azevedo y A. M. Pereira (Coords.), Palavras da crítica contemporânea (pp. 69-88). Salvador: Boto-cor-de-rosa arte e café / paralelo $13 S$.

Ferrero Horach, A. (2014, septiembre 28). Arte contemporáneo y público; una historia de amor entre la queja y el reproche UOC. Recuperado de https://www.youtube.com/watch?v=uGsnFpsf1ro\&t=114s

Han, B.-C. (2018). El aroma del tiempo: un ensayo filosófico sobre el arte de demorarse (Paula Kuffer, trad.). Barcelona, España: Herder Editorial.

Koren, L. (2017). Wabi-Sabi: nuevas consideraciones (Marc Jiménez Buzzi, trad.). Barcelona, España: Sd-edicions.

Marcos, C. y Martínez, C. (2011). El alma en la mano: artesanos y escultores de México y Valencia. Valencia, España: Editorial Universitat Politècnica de València.

Ovidio, P. (2013). Metamorfosis (Ely Leonetti Jungl, trad.). Barcelona, España: Espasa Libros.

Safrannski, R. (2017). La dimensión temporal y el arte de vivir (Raúl Gabás, trad.). Barcelona, España: Tusquets Editores.

Sala, T.-M. (2017). Metamorfosis creativas: evocaciones de la naturaleza en las artes de 1900. En D. López del Rincón (ed), Naturalezas mutantes: del Bosco al bioarte (p. 179-196). Buenos Aires: Sans Soleil Ediciones, Vitoria-Gasteiz.

Thornton, S. (2015). O que é um artista: nos bastidores da arte contemporânea com Ai Weiwei, Marina Abramovic, Jeff Koons, Maurizio Cattelan e outros (Alexandre Barbosa de Souza, trad.). Rio de Janeiro, Brasil: Zahar.

Trigo, L. (2009). A grande feira: uma reação ao vale-tudo na arte contemporânea. Rio de Janeiro, Brasil: Record.

Vieira, C. M. y Marques, K. (2011). Arte contemporânea e seus públicos. Fortaleza, Brasil: Edições Demócrito Rocha.

Virilio, P. y Baj, E. (2010). Discurso sobre el horror en el arte. Madrid, España: Casimiro Libros.

Zamboni, S. (2001). A pesquisa em arte; um paralelo entre arte e ciência. Campinas, Brasil: Autores Associados.

Zoladz, R. (2011). Profissão artista. Rio de Janeiro, Brasil: Aeroplano. 